Proceedings

\title{
How to Solve the Problems of Flipped Teaching Applied to Projects ${ }^{+}$
}

\author{
María Vaquero-Domínguez \\ IESO Tomás Bretón, C/ Escuelas Menores s/n, 37185 Villamayor de Armuña, Spain; mvaquero@gmail.com; \\ Tel.: +34-923-305-660 \\ + Presented at the 2nd Innovative and Creative Education and Teaching International Conference \\ (ICETIC2018), Badajoz, Spain, 20-22 June 2018.
}

Published: 30 October 2018

\begin{abstract}
The flipped classroom model has become very popular in the last five years. The benefits of adopting this methodology can be very attractive for those teachers willing to improve both the engagement of the students and their academic results. However, there are some risks that should be known before transforming a traditional class into a flipped one. In this paper a set of guidelines for applying the flipped model to project-based courses is provided. These recommendations are the result of the lessons learned in a pilot experience with a secondary school that may be useful for other teachers and scholars.
\end{abstract}

Keywords: flipped classroom; high schools; technology projects

\section{Introduction}

The inverted class [1] is a novel educational trend that constitutes a methodology where the active participation of students in the learning process stands out. However, the application in the classroom is not easy due to the drastic change that this methodology implies, the student is the center and must commit to perform a task that in many occasions requires the oral presentation of a work or investigation. This is an important challenge that requires great motivation and interest and not only the mastery of computer tools, but social skills such as assertiveness, knowing how to express oneself in public, etc.

Although flipped classroom does not require an expensive infrastructure-a classroom equipped with computers and internet is sufficient-, it implies a change of mentality. The student must perform previous work and sometimes students who are not familiar with the methodology feel very lost and unmotivated. I present here some guidelines to implement this methodology to class projects.

The rest of the article is or organized as follows: In the following section, I present different guidelines that have proven to be very useful when transforming a technology course into a flipped classroom. Section 3 is devoted to discussing an example of flipped-projects pilot study. Finally, Section 4 outlines the main conclusions reached.

\section{Guidelines for the Teacher of a Flipped-Oriented Project Classroom}

First, if the project is carried out as a group, it is essential to use cooperative learning when creating the groups. Promoting the multiple abilities of the students, that is, not forming homogenous groups in terms of skills, but groups where creativity, leadership, ability to help, social skills, etc. are combined. Once the groups are formed, a fluid cooperation between the students and between the teacher is fundamental, especially in the first part of the process, i.e., self-learning. 
Depending on the educational stage in which the students find themselves, the performance of the teacher in this first phase may be reduced.

The use of educational platforms, such as Edmodo [2] or Yammer [3], where students can have continuous communication with the teacher and their classmates outside of class hours has proven to be very useful. One crucial benefit is that the teacher can publish a guide of the activities and objectives that the student should follow and can consult at any time. On the other hand, the so-called wall of these platforms can be used to raise questions or frequent doubts and share difficulties related both to the project itself that students face and to the computer tools to be used. In this sense the student and the teacher have the same role, can answer questions or propose solutions in the same way. That is, students will post their answers, making possible the review of all the answers through whiteboards and provide instant feedbacks to every student. This practice makes lessons more engaging, collaborative and fun.

Another point to emphasize is to let the students familiarize with the theory of the multiple intelligences of Howard Gardner [4] that established that academic intelligence (the academic record or holding a title) is not a decisive factor to assess the intelligence of a person. Understanding how interacting with other people is as important as obtaining good academic qualifications. All the activities that follow the flip teaching methodology in addition to improving their personal relationships, improve their linguistic intelligence as well as the body and kinesthetic intelligences. Students must know the objectives of this type of activities and the non-academic repercussion (they act beyond higher academic success), i.e., they will help to better manage other facets of their life. Overall, this type of activities is separated from the traditional methodology by encouraging multiple intelligences in preparation for the world of work or subsequent studies.

In the event that one task requires an oral presentation or an activity such as a roll play of a character or a literary fragment, it is essential that the teacher detects before the start of the project those students who, due to shyness or lack of habit, struggle with this additional effort and present a negative attitude towards that part of the work. In order to make this part less difficult and more attractive for this type of student it would be convenient to create a resource bank with recordings where not only the work is presented but also include fail shots so that the students face the task with humor and they lose the scenic fear. It is essential to locate students who have experience or like to speak in public to be distributed in groups and they are the ones who carry the greatest weight of the presentation or oral presentation and support students with less social skills.

It is also important to note that it is not necessary to carry out some personal work at home, but can be developed in the classroom. However, this requires an adequate work environment, marked by an interest in learning and when a question arises about the software being used or the project, students can consult their classmates or the teacher, which will act just as another student.

This technique is not as guided and inflexible as the traditional methodologies, and sometimes it can imply a lack of organization that turns into a problem assuming in many occasions the students lose time in the classroom or do not reach the objectives in time. To tackle this situation, using the calendar offered by these educational platforms mentioned before is essential. In it the teacher can publish the objectives that must be achieved in each session, giving the steps to follow in the short term.

Another essential aspect is that the students see how the result is gradually achieved. In order that the students understand that a project is not a final result (a video, a presentation, a document), but a project has several phases and that the sketches, the scripts, the image gallery that will later be incorporated into the presentation are also part of the project.

To conclude, as the individual projects of the students or groups of students are carried out, they will be published on the platform, creating a virtual learning community where the creation of a resource bank is fundamental for the development of future projects.

\section{Discussion}

As an example, we show a final project carried out by students of a secondary school in the ICT subject, where students show mastery of different free distribution tools such as text, graphic and video editors, as well as knowledge about a painting. 
The project has a series of steps: the first step consists in searching and selecting a portrait. In this phase, the students are encouraged to expand their search so that they choose not only the famous portraits but other interesting ones that are not as well known. The final choice of the portrait must be made by the student in order to make the painting attractive to them since they will then have to represent the character (see Figure 1). It is important to devote sufficient time to this stage and Google Art [5] can be used as a supporting tool. Students can take a virtual tour of the museum where their painting is displayed or visit a museum and look for a portrait they like. Once the portrait has been selected they have to make a text document with relevant information about it, author, his career, style, time, museum where it is displayed and anecdotes or curious details about it. Once the teacher has reviewed the documents, the students are characterized as the person in the painting, prepare a script that they must memorize with the information they are going to record. The recording is done with the chroma technique. As the background of the video, the original picture appears without the character. This part can be done with the free distribution software Gimp [6].

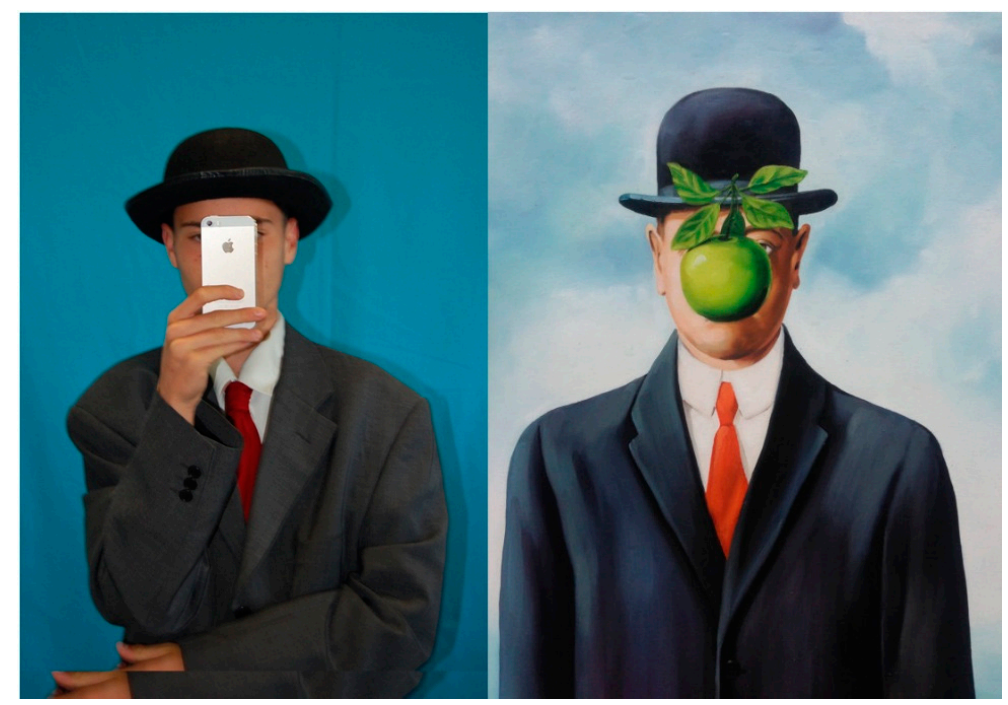

Figure 1. Example of a student in the process of enacting Le Fils de l'Homme (René Magritte, 1964).

Finally, an exhibition with the portraits is carried out in such a way that, combining the use of a tablet or smart phone and the augmented reality technique [7] when the exhibition visitors point the camera of their devices, it recognizes the painting and the explanatory video made by each student appear on top of the painting (see Figure 2).

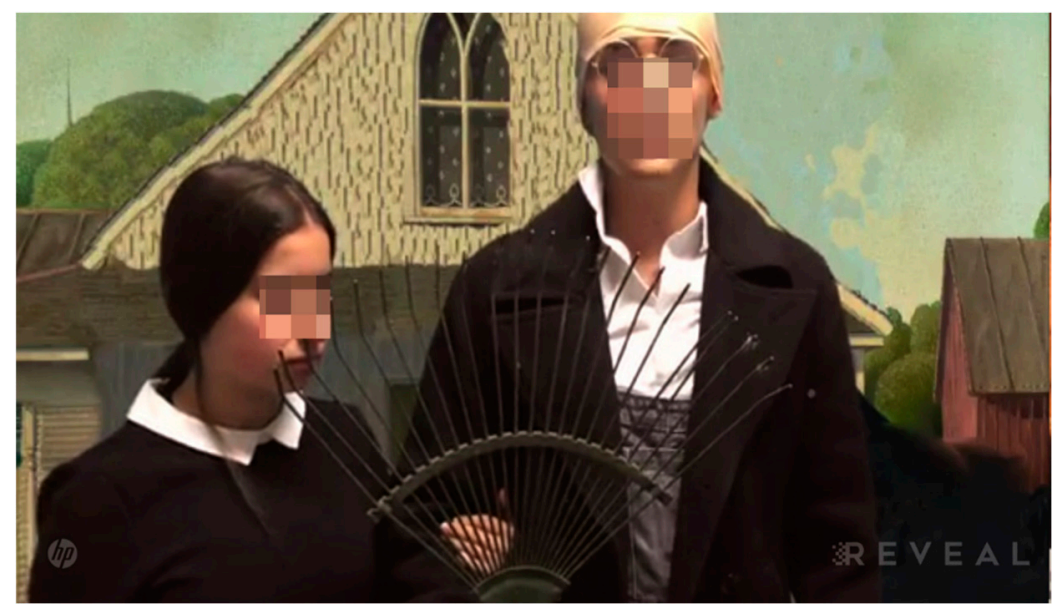

Figure 2. The result of one project: any person with a mobile phone or tablet, using the HP Reveal app, can access an augmented reality video that shows the characters of a painting (in this case, American Gothic, by Grant Wood, 1930) coming alive and explain the historical and cultural context of the master piece (the face of the students has been pixelated to ensure anonymity). 


\section{Conclusions}

The flipped classroom model is not as guided and inflexible as traditional methodologies, and sometimes it can imply a lack of organization that turns into a problem assuming that many times the students lose time in the classroom or do not reach the objectives in time. Overall, the pilot experience has been successful and the performance of students has increased.

Author Contributions: M.V. conceived and designed the pilot project and wrote the paper.

Acknowledgments: The author wishes to acknowledge the support of the IESO Tomás Bretón and the students that collaborated enacting the characters in the paintings.

\section{References}

1. Tucker, B. The flipped classroom. Educ. Next 2012, 12, 82-83.

2. Gardner, H. Frames of Mind: The Theory of Multiple Intelligences; Basic Books: New York, NY, USA, 2011.

3. Edmodo. Available online: https://www.edmodo.com/ (accessed on 30 May 2018).

4. Yammer. Available online: https://www.yammer.com/ (accessed on 30 May 2018).

5. Google Art. Available online: https://artsandculture.google.com/ (accessed on 30 May 2018).

6. GIMP. Available online: https://www.gimp.org/ (accessed on 30 May 2018).

7. HP Reveal. Available online: https://www.hpreveal.com/ (accessed on 30 May 2018).

(C) 2018 by the author. Licensee MDPI, Basel, Switzerland. This article is an open access article distributed under the terms and conditions of the Creative Commons Attribution (CC BY) license (http://creativecommons.org/licenses/by/4.0/). 